Tersedia online di: http://ejournal-balitbang.kkp.go.id/index.php/jkpi
e-mail:jkpi.puslitbangkan@gmail.com
JURNAL KEBIJAKANPERIKANANINDONESIA
Volume 8 Nomor 2 Nopember 2016
p-ISSN: 1979-6366
e-ISSN: 2502-6550
Nomor Akreditasi: 626/AU2/P2MI-LIPI/03/2015

\title{
STATUS PEMANFAATAN DAN UPAYA PELESTARIAN IKAN ENDEMIK AIR TAWAR DI PULAU SUMATERA
}

\section{THE UTILIZATION STATUS AND CONSERVATION EFFORT OF ENDEMIC FRESHWATER FISHES IN SUMATRA ISLAND}

\author{
Eko Prianto*, Reni Puspasari, Dian Oktaviani dan Aisyah \\ Pusat Penelitian dan Pengembangan Perikanan, Gedung Balitbang KP II, Jl. Pasir Putih II, Ancol Timur, Jakarta Utara-14430, Indonesia \\ Teregistrasi I tanggal: 15 April 2014; Diterima setelah perbaikan tanggal: 07 Desember 2016; \\ Disetujui terbit tanggal: 09 Desember 2016
}

\begin{abstract}
ABSTRAK
Ikan endemik Pulau Sumatera tersebar di beberapa wilayah dengan tipe habitat yang berbedabeda. Saat ini beberapa jenis ikan endemik terancam punah akibat degradasi lingkungan, hilang atau berubahnya habitat dan eksploitasi yang berlebihan. Tujuan penulisan untuk mengetahui status sumberdaya ikan endemik Pulau Sumatera dan upaya pelestariannya. Metodologi pengumpulan data dan informasi dilakukan dengan studi literatur yang dianalisis secara deskriptif. Hasil sintesis menunjukkan, jumlah jenis ikan endemik di Pulau Sumatera mengalami peningkatan disebabkan adanya penemuan jenis ikan baru selama 20 tahun terakhir. Komposisi jenis ikan endemik Sumatera sebanyak 66 jenis yang terdiri dari 13 famili dan didominasi oleh famili Cyprinidae sebanyak 21 jenis dan famili Osphronemidae sebanyak 16 jenis. Status pemanfaatan ikan endemik Pulau Sumatera terdiri dari genting (critically endangered) sebanyak 5 jenis, rawan ( vulnerable) sebanyak 7 jenis, bahaya (endangered) sebanyak 1 jenis, kurang data (data deficient) sebanyak 1 jenis dan belum dievaluasi (not evaluated) sebanyak 52 jenis. Untuk menjaga kelestarian sumberdaya ikan endemik di Pulau Sumatera diperlukan pelestarian secara in-situ dan ex-situ. Upaya pelestarian secara in-situ diantaranya melalui: a) suaka perikanan, b) rehabilitasi lingkungan dan modifikasi habitat, c) pengendalian ikan introduksi, d) menyusun regulasi penangkapan ikan sedangkan ex-situ yaitu melalui domestikasi. Sebagai rekomendasi kedepannya perlu upaya perlindungan melalui: i) penyusunan regulasi tentang perlindungan habitat ikan endemik dan upaya konservasi jenis ikan: dan ii) pengembangan hatchery untuk domestikasi dan re-stocking.
\end{abstract}

\section{Kata Kunci: Status; ikan endemik; Pulau Sumatera}

\begin{abstract}
Freshwater endemic fish of Sumatra island are distributed and inhabitedt in various habitat. The sustainability of this fish are under threat due to environmental degradation, habitat modification and loss, also over exploitation. Desk study in order to understand the conservation state and effort of this freshwater endemic fishes in Sumatra Island was conducted by collecting secondary data and literature review then analyzed descriptively. There is an increment number of freshwater endemic fish with several new species are recorded during the last two decades. The endemic fishes recorded in Sumatera Island are 66 species from 13 different families. Cyprinidae is the most dominant family consisting of 21 species followed by Osphronemidae consisting of 16 species. The conservation state of this freshwater endemic fish is divided into five categories; critically endangered (5 species), vulnerable (7 species), endangered (1 species), data deficient (1 species) and not yet evaluated (52 species). To date, the conservation management of endemic fishes in Indonesia, specially in Sumatra Island is still limited. Therefore, management effort, such as in-situ and ex-situ conservation should be proposed in the near future. In-situ fish conservation are: a) fish sanctuary or conservation, b) environmental rehabilitation and habitat modification, c) introduction
\end{abstract}


of fish controlling, d) arrangement of fishing regulation. Ex-situ fish conservation can be carried out through domestication program. it is also recommendated that the preservation of the are endemic fishes can be done through: i) arrangement of endemic fishes habitat regulation and conservation and ii) support for hatchery development, domestication and re-stocking programs.

Keywords: Endemic fishes; Sumatera Island, Status

\section{PENDAHULUAN}

Secara geografis daerah penyebaran ikan air tawar di Indonesia terbagi menjadi tiga yaitu: Paparan Sunda, daerah Wallacea, dan Paparan Sahul. Kottelat \& Whitten, (1996) memperkirakan jumlah spesies ikan air tawar di Indonesia sekitar - \pm 1.300 spesies, yang merupakan jumlah tertinggi di Benua Asia. Lebih jauh dikatakan bahwa biodiversitas spesies ikan air tawar Indonesia nomor dua terkaya di dunia setelah Brazil yang kekayaan spesiesnya mencapai +3.000 spesies.

Para ahli memperkirakan masih ada sekitar ratusan spesies ikan di wilayah Indonesia yang belum ditemukan dan dideskripsikan (Wargasasmita, 2002). Kottelat et al. (1993) menyatakan bahwa Pulau Kalimantan memiliki lebih dari 394 jenis ikan dan sebanyak 149 jenis merupakan ikan endemik (38\%), Pulau Sumatera memiliki 272 jenis dengan 30 jenis yang endemik (11\%) dan Pulau Jawa berjumlah 132 jenis dengan 12 jenis yang endemik (9\%).

Ikan endemik adalah jenis ikan tertentu yang hanya memiliki sebaran geografis alami terbatas dan/ atau karakteristik ekosistem tertentu sedangkan ikan asli adalah ikan dan/atau sumber daya ikan lainnya yang berasal dari alam Indonesia yang dikenali dan/ atau diketahui berasal dari alam darat Indonesia dan berasal atau hidup di daerah tertentu dan/atau berbeda ekosistemnya di wilayah perairan Indonesia (Direktorat Kawasan Konservasi Jenis Ikan, 2015).

Ikan-ikan endemik di Pulau Sumatera tersebar di beberapa wilayah dan mendiami tipe habitat yang berbeda-beda. Namun, keberadaannya saat ini telah mengalami penurunan akibat degradasi lingkungan, hilang atau berubahnya habitat, introduksi ikan asing dan eksploitasi yang berlebihan (Muchlisin et al., 2013). Degradasi lingkungan yang mengancam kelestarian sumberdaya ikan disebabkan oleh alih fungsi lahan, eksploitasi berlebihan, persaingan penggunaan air, pembuangan limbah dari aktivitas perindustrian, pemukiman, pertanian dan perkebunan; hilangnya habitat ikan karena pembendungan dan pelurusan sungai (Moyle \& Leidy, 1992) serta perubahan iklim (Engelman et al., 2008).Selain itu, eksploitasi sumberdaya ikan dengan menggunakan alat tangkap yang merusak dan berlebihan tanpa memperhatikan kelestarian sumberdaya ikan telah menyebabkan penurunan sumberdaya bahkan beberapa tempat terjadi kelangkaan sumberdaya ikan (Utomo et al., 2008).

Berbagai informasi diperlukan dalam upaya konservasi biodiversitas, termasuk manfaat bagi manusia, distribusi, status, kecenderungan ancaman gangguan, dan hubungan ekologis. Penentuan kawasan lindung tidak akan tepat sasaran bila tidak disertai pengetahuan yang baik tentang distribusi jenis yang memungkinkan penentuan prioritas kawasan konservasi (McNeely et al., 1990; Kerr, 1996 dalam Wargasasmita, 2002). Tulisan ini bertujuan untuk mengetahui status pemanfaatan sumberdaya ikan endemik Pulau Sumatera dan upaya pelestariannya yang berguna sebagai dasar dalam pengelolaan ikan endemik.

\section{KERAGAMAN JENIS IKAN ENDEMIK PULAU SUMATERA}

Pulau-pulau kecil dan pegunungan biasanya mempunyai keanekaragaman jenis yang rendah, tetapi mempunyai endemisitas yang tinggi (Groombridge, 1992). Data yang disajikan oleh Wargasasmita (2002) menunjukkan bahwa jenis ikan air tawar yang menghuni ekosistem air tawar Sumatera berjumlah 546 jenis dengan 16,8\% digolongkan sebagai ikan endemik Sumatera. Jenis ikan endemik Sumatera paling banyak berasal dari suku Cyprinidae yaitu 21 jenis. Masing-masing suku memiliki tingkat endemisitas yang berbeda (Gambar 1). Tingkat endemisitas tertinggi dari suku Belontiidae (42,3\%), sedangkan yang terendah dari suku Siluridae (3,8\%). Zakaria-Ismail (1994) juga menyatakan bahwa suku Belontiidae mempunyai tingkat endemisitas paling tinggi di Sumatera termasuk Kalimantan dan Jawa.

Seiring perkembangan dan penemuan jenis ikan baru, hasil analisa data dari Lumbantobing. (2014), Wargasasmita. (2002), http://fishbase.org (2015), Hui. (1999), Kottelat et al. (1993), Kottelat. (1991), Conservation Breeding Specialist Group (2003), diperoleh jenis ikan endemik di Pulau Sumatera sebanyak 66 jenis dari 13 suku (Gambar 2) Jenis ikan endemik paling banyak ditemukan pada suku Cyprinidae berjumlah 21 jenis yang diikuti Osphronemidae berjumlah 16 jenis. Jumlah suku yang memiliki jenis ikan endemik lebih banyak dari pada data yang disampaikan oleh Wargasasmita. (2002) 
sebanyak 1 suku. Jenis-jenis ikan endemik di Pulau Sumatera dan sebarannya dapat dilihat pada Lampiran 1.

\section{SEBARAN IKAN ENDEMIK PULAU SUMATERA}

Cakupan wilayah Sumatera di dalam tulisan ini meliputi Pulau Sumatera beserta pulau-pulau kecil di sekitanya. Data yang ada menunjukkan bahwa sebaran jenis ikan air tawar endemik ditemukan di seluruh wilayah Sumatera, baik itu tersebar hanya pada pulau ataupun perairan tertentu saja (Wargasasmita, 2002; Kottelat et al., 1993; Lumbantobing, 2014; http:/ /fishbase.org 2015). Provinsi yang memiliki jenis ikan endemik terbanyak adalah Sumatera Utara dengan jumlah 19 jenis (Tabel 1 ).

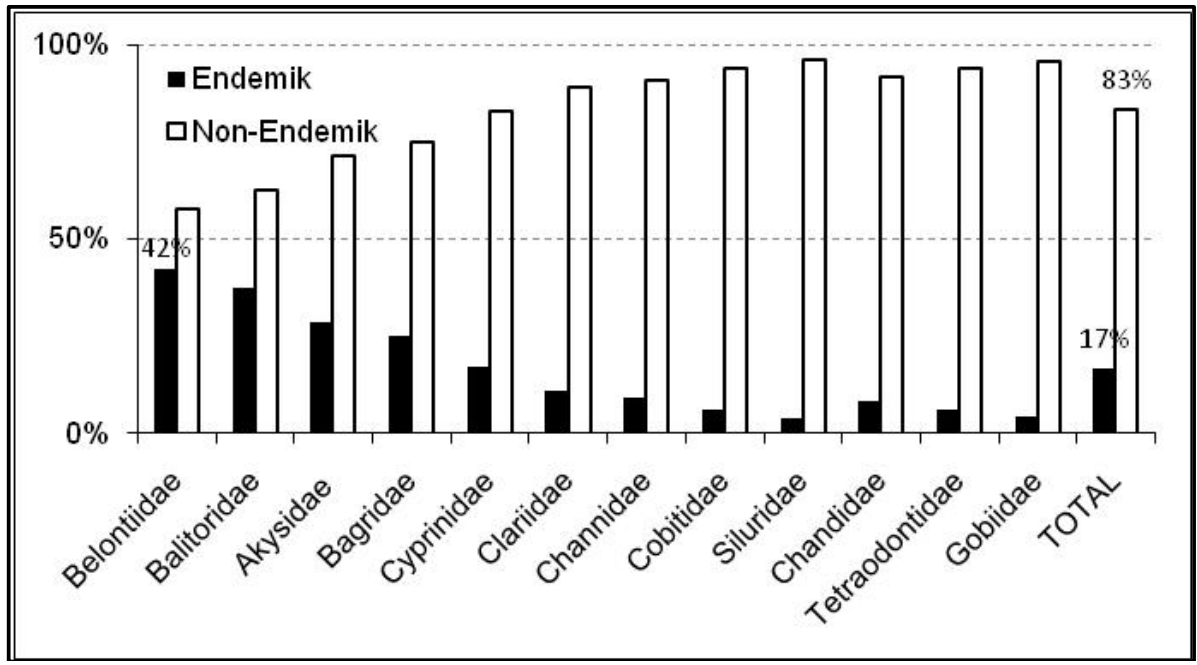

Gambar 1. Tingkat endemisitas ikan air tawar Sumatera per suku. (sumber: Wargasasmita, 2002). Figure 1. Endemicity of fresh water fishes in Sumatra by family. (source: Wargasasmita, 2002).

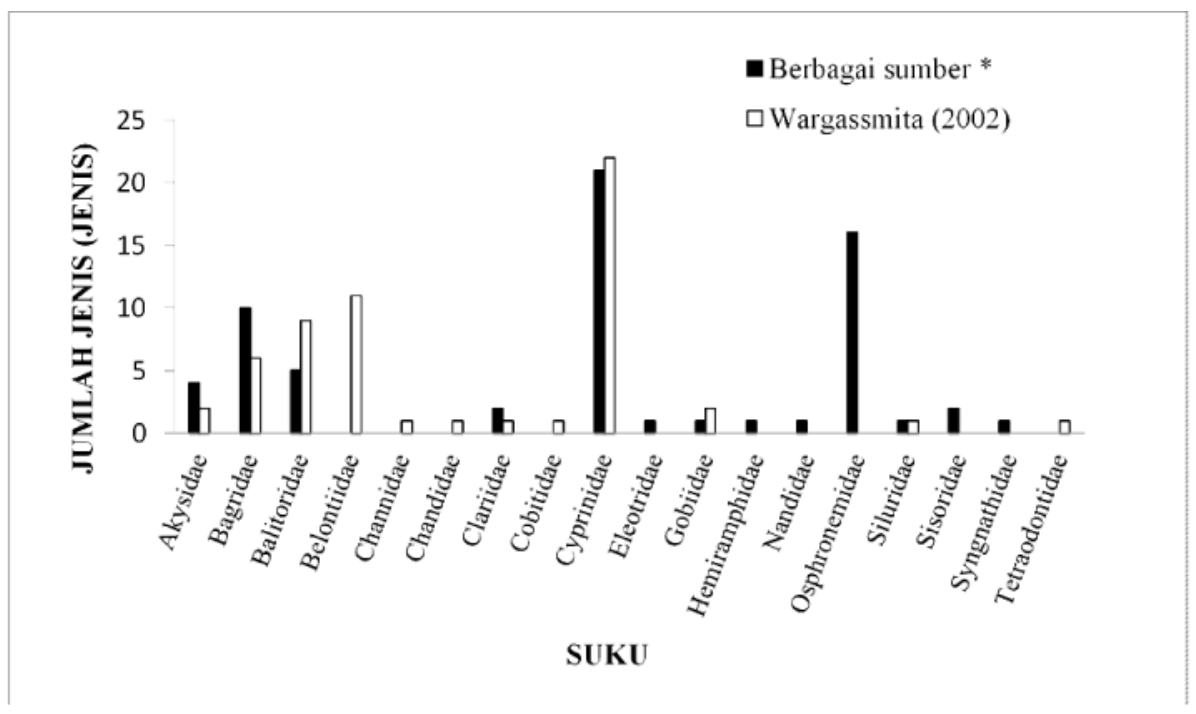

Catatan/Annotation: *Lumbantobing (2014), Wargasasmita (2002), http://fishbase.org (2015), Hui (1999), Kottelat et al. (1993), Kottelat, (1991), CBSG, (2003).

Gambar 2. Suku-suku yang memiliki jenis ikan air tawar endemik di Sumatera.

Figure 2. The families are having endemic freshwater species in Sumatera. 
Tabel 1. Jumlah jenis ikan endemik per provinsi di Sumatera

Table 1. The number of endemic freshwater fishes in Sumatra by province

\begin{tabular}{|c|c|c|c|c|}
\hline $\begin{array}{c}\text { No/ } \\
\text { Number }\end{array}$ & $\begin{array}{l}\text { Provinsi/ } \\
\text { Province }\end{array}$ & $\begin{array}{l}\text { Jumlah Jenis } \\
\text { Ikan Endemik/ } \\
\text { Amount of } \\
\text { Endemic Fishes }\end{array}$ & $\begin{array}{l}\text { Jenis Ikan Endemik Lokal/ } \\
\text { Species of Local Endemic }\end{array}$ & $\begin{array}{l}\text { Distibusi/ } \\
\text { Distribution }\end{array}$ \\
\hline 1. & $\begin{array}{l}\text { Nangroe Aceh } \\
\text { Darussalam }\end{array}$ & $7^{*}$ & $\begin{array}{l}\text { Poropuntius tawarensis* } \\
\text { Rasbora tawarensis }\end{array}$ & $\begin{array}{l}\text { Danau Laut } \\
\text { Tawar }\end{array}$ \\
\hline 2. & Sumatera Utara & $19^{*}$ & $\begin{array}{l}\text { Neolissochilus thienemanni* } \\
\text { Rasbora tobana** }\end{array}$ & Danau Toba \\
\hline 3. & Sumatera Barat & $10^{*}$ & $\begin{array}{l}\text { Mystacoleucus } \\
\text { padangensis }{ }^{* *} \\
\text { Rasbora maninjau }^{\star * *}\end{array}$ & $\begin{array}{l}\text { Danau } \\
\text { Singkarak } \\
\text { Danau } \\
\text { Maninjau }\end{array}$ \\
\hline 4. & Riau & $6^{*}$ & & \\
\hline 5. & Kepulauan Riau & $6^{*}$ & $\begin{array}{l}\text { Betta miniopinna* } \\
\text { B. spilotogena* }\end{array}$ & Pulau Bintan \\
\hline 6. & Jambi & $13^{*}$ & & \\
\hline 7. & $\begin{array}{l}\text { Sumatera } \\
\text { Selatan }\end{array}$ & $6^{*}$ & & \\
\hline 8. & Bengkulu & 1 & & \\
\hline 9. & Lampung & $3^{*}$ & & \\
\hline 10 & Bangka Belitung & $6^{*}$ & $\begin{array}{l}\text { Betta burdigala* } \\
\text { B. chloropharyn } x^{\star} \\
\text { Encheloclaris tapeinopterus* }\end{array}$ & Pulau Bangka \\
\hline
\end{tabular}

Catatan/Annotation: * Wargasasmita (2002); ** Kottelat et al. (1993); ** Lumbantobing (2014)

Habitat ketiga belas jenis ikan air tawar endemik Sumatera yang terancam punah adalah Danau Laut Tawar ( 2 jenis), Danau Toba ( 2 jenis), Pulau Bintan ( 3 jenis), Pulau Nias ( 1 jenis), Sibolga ( 1 jenis) dan Pulau Bangka (4 jenis) (Wargasasmita, 2002; Kottelat et al., 1993 \& Kottelat, 1991, Conservation Breeding Specialist Group, 2003). Di Danau Laut Tawar Propinsi Nangroe Aceh Darussalam ditemukan dua jenisikan endemik antara lain ikan depik (Rasbora tawarensis) dan kawan (Poropuntius tawarensis) (Muchlisin, 2013). Hingga saat ini upaya pelestarian dan domestikasi ikan endemik di Danau Laut Tawar terus diupayakan agar keberadaannya tetap lestari. Selanjutnya di Danau Toba terdapat ikan ihan/batak (Neolissochilus thienemanni), yang saat ini dialam jarang ditemukan lagi. Rasbora tobana. Ikan batak mempunyai nilai tersendiri di masyarakat disekitar Danau Toba dan biasanya digunakan untuk upacara adat atau pernikahan, ikan batak dimasukkan sebagai persyaratan dalam upacara tersebut.

Selain jenis ikan ekonomis penting tersebut, keberadaan ikan endemik di Pulau Sumatera juga berfungsi sebagai sumber plasma nutfah. Beberapa jenis ikan yang dilaporkan merupakan ikan endemik adalah jenis tempalo seperti Beta miniopinna, $B$. spilotogena dan Parosphomenus bintan yang ditemukan di Kepulauan Riau serta Betta burdigala, B. chloropharynx, B. schalleri dan Parosphomenus deissneri di Bangka-Belitung (Wargasasmita, 2002; Conservation Breeding Specialist Group, 2003). Selain itu, di perairan rawa Tasik Serkap Propinsi Riau ditemukan ikan merah (Pectenocypris nigra) sebagai jenis ikan baru dan endemic (Prianto et al., 2014; Wibowo, Ahnelt \& Kartamihardja, 2016). Menurut Kottelat et al. (2006) bahwa di Pulau Sumatera ditemukan jenis ikan terkecil di dunia (Paedocypris progenetica) yang hidup di perairan rawa Pematang Lumut Provinsi Jambi dan berstatus endemik.

\section{STATUS STOK IKAN ENDEMIK SUMATERA}

Keberadaan spesies endemik pada suatu ekosistem tentunya akan menjadi pusat perhatian bagi masyarakat dan peneliti terhadap ekosistem tersebut. Akan tetapi, ancaman terhadap eksistensi dari spesies endemik akan lebih besar dibandingkan dengan spesies yang non endemik. Hal ini dikarenakan populasinya sangat terbatas secara biogeografis. Apalagi ditambah dengan proses degradasi habitat yang menjadi tempat tinggalnya. Saat ini, tingkat ancaman kepunahan yang diklasifikasikan oleh IUCN menjadi dasar pengelompokkan status populasi suatu spesies. Status dari suatu spesies 
yang beresiko kepunahan (extinction risk) dapat ditentukan setelah dilakukan evaluasi berdasarkan pada data yang valid (adequate data). Tingkat resiko kepunahan terdiri dari lima tingkatan dengan kategori terancam (threatened category) terdiri dari tiga tingkatan, yaitu rentan/rawan (vulnerable, VU), bahaya (endangered, EN), dan genting/kritis (critically endangered, CR) (Gambar 3).

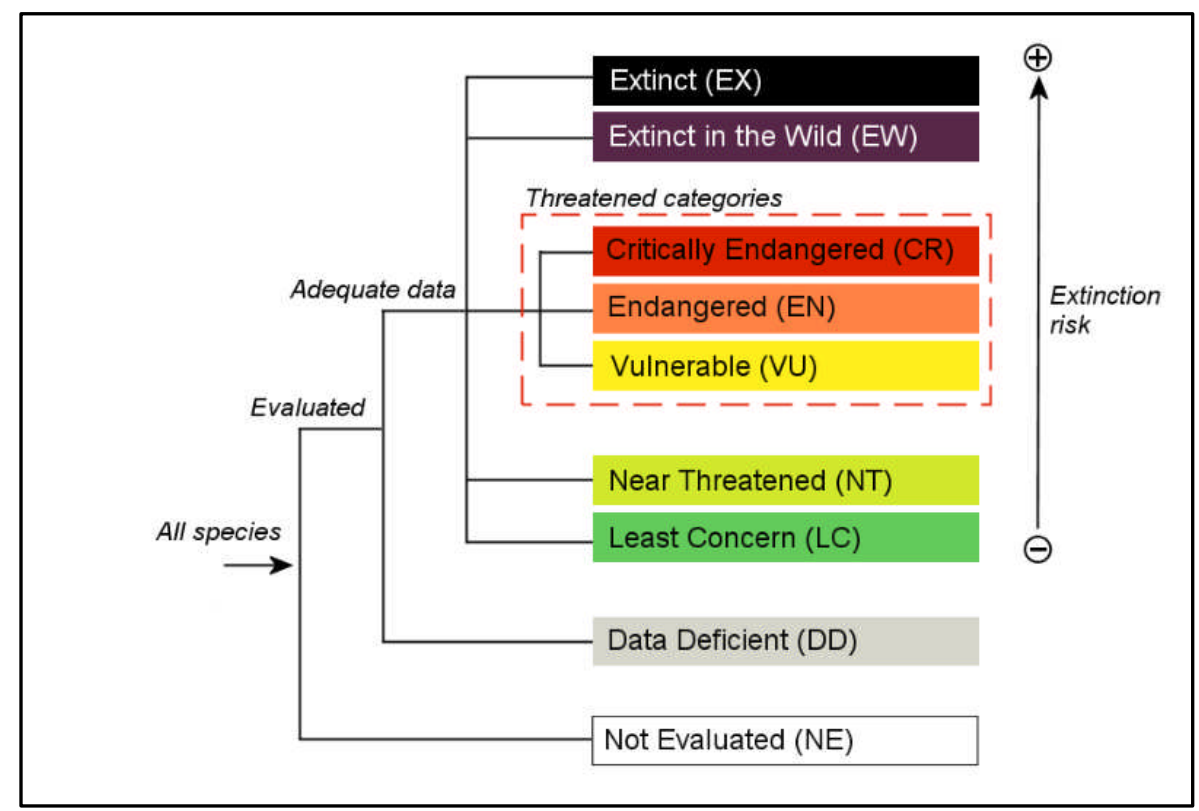

Gambar 3. Struktur kategori IUCN red list (IUCN, 2016).

Figure 3. The category structure of IUCN red list (IUCN, 2016).

Data yang diperoleh memperlihatkan bahwa status populasi jenis ikan endemik Sumatera berada pada tingkat rentan hingga genting (Wargasasmita, 2002). Sementara itu, Lumbantobing (2014) menyatakan bahwa beberapa jenis lainnya berstatus not evaluated (belum dievaluasi). Gambaran status dari beberapa ikan endemik Sumatera berdasarkan kategori resiko kepunahan, sebagai berikut:

\section{a. Genting/kritis (critically endangered)}

Genting (critically endangered) merupakan status konservasi yang diberikan kepada spesies yang menghadapi risiko kepunahan di waktu dekat. Kelompok ikan yang termasuk kategori kritis (critically endangered) di Pulau Sumatera adalah ikan beta yaitu Betta miniopinna, B. spilotogena dan Parosphomenus bintan yang ditemukan di Pulau Bintan Propinsi Kepulauan Riau (Wargasasmita, 2002) serta Parosphomenus deissneri di Pulau Bangka dan Betta rubra di Sumatera Utara (Conservation Breeding Specialist Group, 2003).

Penyebab kritisnya status ikan Betta miniopinna, B. spilotogena dan Parosphomenus bintan di Pulau Bintan karena alih fungsi lahan rawa untuk pengembangan pariwisata seperti pengembangan lapangan golf, resort dan sebagainya serta pembukaan hutan untuk perkebunan karet.
Pembangunan resort dan lapangan golf yang intens dilakukan banyak mengkonversi lahan rawa sehingga habitatnya semakin sempit. Penyebab kritisnya status ikan Parosphomenus deissneri, karena di Pulau Bangka maraknya penambangan timah illegal yang menyebabkan meningkatnya pencemaran dan sedimentasi (Prianto \& Husnah, 2009).

\section{b. Dalam Bahaya (endangered)}

Kelompok dalam bahaya (endangered) berarti spesies yang tidak termasuk kedalam kategori kritis dan menghadapi resiko kepunahan di alam sangat tinggi dalam waktu dekat. Kelompok ikan endemik yang termasuk kedalam kategori endangered adalah Rasbora reticulata yang ditemukan di Pulau Nias Provinsi Sumatera Utara (Conservation Breeding Specialist Group, 2003). Penyebab langkanya jenis ikan ini akibat alih fungsi lahan untuk perkebunan dan pertanian.

\section{c. Rentan/rawan (vulnerable)}

Kelompok rawan (vulnerable) berarti kondisi rentan (VU) merupakan batas awal dari status konservasi atas flora dan fauna yang dinyatakan berada dalam ambang kepunahan. Kelompok ikan yang termasuk ke dalam kategori rawan (vulnerable) adalah ikan beta (Betta burdigala, B. schalleri dan B. chloropharynx) 
yang ditemukan di Pulau Bangka, ikan batak (Neolissochilus thienemanni) dan Rasbora tobana (Danau Toba, Sumatera Utara), Poropuntius tawarensis dan Rasbora tawarensis (Danau Laut Tawar, Aceh) (Wargasasmita, 2002; Kottelat et al., 1993; Kottelat, 1991).

Jenis-jenis ikan yang termasuk kategori rawan merupakan jenis yang mendiami habitat terbatas (danau) atau terisolasi pada pulau terpencil (seperti Bangka) dengan tekanan ekologi yang tinggi. Ikanikan yang mendiami perairan terbatas tersebut tidak mampu melakukan migrasi ke perairan lain. Ikan Betta burdigala, B. chloropharynx dan B. schalleri merupakan kelompok ikan yang mendiami perairan rawa asam di Pulau Bangka. Sejak beberapa tahun terakhir keberadaan rawa dan sungai terancam akibat maraknya penambangan timah illegal. Akibat dari penambangan timah tersebut perairan rawa dan sungai tercemar bahan polutan, kekeruhan meningkat dan tingginya sedimentasi (Prianto \& Husnah, 2009).

\section{d. Kurang data (data deficient)}

Suatu jenis dinyatakan dalam kondisi kekurangan data apabila diketahui adanya ketidakcukupan informasi yang secara langsung maupun tidak langsung diperlukan untuk menjadi dasar pendugaan atas kriteria risiko kepunahan berdasarkan distribusi dan/atau status populasinya. Taksonomi dari flora dan fauna yang telah terindentifikasi tidak selalu cukup untuk memberikan informasi mengenai keberadaan termasuk peta penyebarannya, sehingga menyebabkan keraguan atas keberadaan flora dan fauna tersebut. Jenis ikan yang termasuk ke dalam kategori tersebut adalah Osteochilus serokan di Sungai Lembang Aceh Selatan (Jenkins, Kullander \& Tan, 2009).

\section{e. Belum dievaluasi (not evaluated)}

Suatu kondisi yang menyatakan apabila jenis yang diidentifikasikan status konservasinya belum dilakukan evaluasi berdasarkan kriteria-kriteria menurut pedoman IUCN Red List. Dalam kasus ini, bisa saja suatu jenis ikan sebenarnya sudah diambang kepunahan namun karena kekurangan data status jenis ikan tersebut belum termasuk kedalam daftar yang harus dilindungi menurut IUCN. Dari 66 jenis ikan endemik di Pulau Sumatera sebanyak 52 jenis ikan termasuk kategori belum dievaluasi.

\section{UPAYA PELESTARIAN IKAN ENDEMIK}

Pengelolaan ikan-ikan endemik di Pulau Sumatera masih sedikit dilakukan. Sebagian besar jenis ikan endemik tidak dikelola dengan baik sehingga keberadaannya saat ini dialam terancam punah dan mulai langka bahkan ikan ihan/batak (Neolissochilus thienemanni) sudah sangat sulit ditemukan lagi dialam. Namun demikian, beberapa jenis ikan yang telah diupayakan untuk dikelola dengan baik seperti ikan depik (Rasbora tawarensis) dan kawan (Poropuntius tawarensis) di Danau Laut Tawar tepatnya di Teluk One-one dan Kampung Mengaya (Kutarga et al., 2008).

Walaupun banyak ikan-ikan endemik yang terancam punah, namun upaya perlindungan dan pelestarian belum ada hingga saat ini. Produk hukum dan peraturan perundang-undangan seperti peraturan daerah mengenai pengelolaan ikan-ikan endemik diseluruh propinsi dan kabupaten di Pulau Sumatera belum ada. Status ikan endemik di beberapa daerah oleh pemerintah daerah masih belum dianggap penting sehingga keberadaannya terabaikan. Predikat sebagai jenis ikan non ekonomis dan ketidaktahuan pemerintah daerah karena kekurangan data dan informasi diduga menjadi alasan pemerintah daerah enggan melakukan upaya-upaya untuk menjaga kelestariannya.

Untuk menjaga kelestarian sumberdaya ikan endemik Sumatera terutama yang terancam punah dapat melalui beberapa upaya. Upaya yang dilakukan sebaiknya disesuaikan dengan hal-hal yang menyebabkan penurunan populasi spesies tersebut di alam. Upaya yang dilakukan secara in-situ dan exsitu.

\section{In-situ}

Upaya untuk melestarikan jenis ikan endemik secara in-situ adalah melakukan suatu upaya pelestarian (konservasi) pada habitat alami spesies tersebut. Adapun kegiatan yang dapat dilakukan sebagai berikut, yaitu:

\section{a. Suaka perikanan}

Pembentukan suaka perikanan ditujukan untuk melindungi habitat ikan endemik, agar terhindar dari upaya penangkapan tehadap jenis tersebut. Suaka perikanan bisa ditetapkan di kawasan yang berfungsi sebagai tempat berlindung/berkembangbiak. Pembentukan suaka perikanan ditujukan agar ikanikan tersebut mampu berkembangbiak secara alami. Pembentukan suaka perikanan biasanya ditujukan untuk jenis ikan yang mengalami eksploitasi berlebihan seperti ikan depik (Rasbora tawarensis) di Danau Laut Tawar dan ikan batak (Neolissochilus thienemanni) di Danau Toba. 
Pengembangan suaka perikanan di Danau Laut Tawar telah tercantum dalam Rencana Tata Ruang Wilayah (RTRW) Kabupaten Aceh Tengah Tahun 2008-2028.Dimana kawasan suaka perikanan seluas \pm $1,5 \%$ dari total luas kawasan, diperuntukkan bagi pelestarian ikan langka dan khas daerah tersebut, yakni ikan depik (Rasbora tawarensis). Kawasan suaka perikanan tersebut dialokasikan di Teluk Oneone dan Kampung Mengaya yang berada di tepi Danau Laut Tawar (Kutarga et al., 2008) sedangkan ikan batak (Neolissochilus thienemanni) di Sungai Asahan (Barus et al., 2014).

\section{b. Rehabilitasi lingkungan dan modifikasi habitat}

Rehabilitasi lingkungan dan modifikasi habitat dilakukan pada habitat ikan endemik yang sudah mengalami penurunan kualitas akibat pencemaran, pembukaan lahan dan penggunaan alat tangkap tidak ramah lingkungan. Opsi rehabilitasi habitat dapat dilakukan untuk melestarikan ikan Betta miniopinna, B. spilotogena, B. burdigala, B. chloropharynx, B. rubra, $B$. schalleri, Poropuntius tawarensis, Rasbora tawarensis, $R$. reticulata, $R$. tobana, Parosphomenus bintan dan $P$. deissneri. Modifikasi habitat untuk memperbaiki laju rekruitmen, pertumbuhan, jalur ruaya/migrasi atau tempat perlindungan ikan endemik.

Beberapa contoh rehabilitasi habitat yang sudah dilakukan seperti pembuatan aliran air baru (penyodetan) pada aliran sungai sebagai tempat pemijahan ikan untuk meletakkan telur-telur ikan depik (Nasution, 2015). Selain itu, rehabilitasi habitat harus dilakukan di Pulau Bangka dan Pulau Bintan. Di Pulau Bangka, rehabilitasi perlu dilakukan pada rawa-rawa dan sungai yang tercemar akibat penambangan timah. Usaha yang dapat dilakukan melalui i) pembuatan kolam penampungan tailing agar tidak langsung dibuang ke sungai atau rawa dan ii) penanaman vegetasi air sebagai tempat perlindungan ikan.Sedangkan di Pulau Bintan, perlu mengurangi alih fungsi lahan untuk pengembangan pariwisata dan lapangan golf. Selain itu, menjaga kelestarian rawa asam dan anak-anak sungai yang ada sebagai habitat ikan Betta miniopinna dan Betta spilotogena.

\section{c. Pengendalian ikan introduksi}

Pengendalian ikan introduksi merupakan salah satu opsi yang dapat dilakukan sebagai upaya pelestarian ikan endemik. Upaya pengendalian introduksi ikan asing dilakukan di lokasi yang telah mengalami perubahan struktur komunitas ikan dari kondisi alaminya, karena masuknya jenis invasif yang menggeser jenis ikan asli perairan tersebut. Pengendalian ikan introduksi dapat diterapkan di
Danau Laut Tawar untuk mengendalikan dominasi ikan nila (Oreochromis niloticus) yang menggeser ikan depik (Rasbora tawarensis). Saat ini upaya pengendalian introduksi ikan asing juga perlu dilakukan di Danau Toba dimana terjadi invasi dari jenis ikan kaca-kaca (Parambassis siamensis) sejak tahun 2014 (Kartamihardja et al., 2015).

\section{d. Menyusun regulasi penangkapan ikan}

Over fishing atau lebih tangkap disebabkan karena adanya pemanfaatan yang berlebihan terhadap sumberdaya ikan tertentu dilakukan masyarakat. Dampak yang ditimbulkan dari over fishing tersebut adalah kelangkaan atau menurunnya stok sumberdaya ikan dialam. Jika eksploitasi dilakukan pada ikan endemik maka dalam jangka panjang dapat menyebabkan kelangkaan atau punahnya jenis ikan tersebut. Untuk melindunginya perlu menyusun regulasi penangkapan ikan. Over fishing telah terjadi pada beberapa jenis ikan seperti ikan batak (Neolissochilus thienemanni) dan ikan depik (Rasbora tawarensis).

Menurut Direktorat KKJI (2015) untuk mengatasi lebih tangkap dapat dilakukan melalui: i) pembatasan jumlah tangkapan berdasarkan jumlah stok dialam dan kemampuan regenerasinya; ii) pengaturan waktu tangkap untuk menghindari tertangkapnya jenis ikan yang sedang dalam musim pemijahan; iii) pembatasan ukuran ikan yang tertangkap agar memberikan peluang setiap individu dapat melakukan regenerasi (memperpanjang keturunannya); iv) pengaturan dan pengawasan alat tangkap yang digunakan supaya tidak merusak populasi maupun habitat ikan tertentu; dan v) penerapan sistem zonasi sehingga dapat menjamin pelestarian ikan.

\section{Ex-situ}

Upaya untuk melestarikan jenis ikan endemik secara ex-situ adalah melakukan suatu upaya pelestarian (konservasi) di luat habitat alami spesies tersebut. Adapun kegiatan yang dapat dilakukan adalah domestikasi. Domestikasi dilakukan untuk melestarikan dan meningkatkan stok ikan yang hampir punah (Yulfiperius, 2006). Domestikasi ikan endemik yang telah dilakukan saat ini mengarah pada kegiatan budidaya dan konservasi. Benih yang dihasilkan dari kegiatan budidaya dapat ditebarkan kembali di habitat aslinya (re-stocking) sehingga eksistensinya masih tetap terjaga (Nur, 2011).

Domestikasi ikan alam memerlukan teknologi untuk mengadaptasi ikan tersebut di tempat terbatas dan terkontrol, sehingga mampu menghasilkan 
generasi yang mampu bertahan dan tumbuh seperti kondisi alaminya. Oleh karena itu, kegiatan domestikasi diharapkan tidak merubah karakteristik fenotip dan genotipnya. Domestikasi perlu dilakukan terutama pada jenis ikan yang masuk kategori rentan seperti Neolissochilus thienemanni. Upaya domestikasi batak/ihan (Neolissochilus thienemanni) pernah dilakukan oleh Balai Penelitian dan Pengembangan Budidaya Air Tawar (BPPBAT) Bogor, namun upaya tersebut belum membuahkan hasil. Saat ini BPPBAT baru berhasil memijahkan ikan semah (Tor soro) yang secara fisik penampilannya mirip dengan ikan batak.

\section{KESIMPULAN DAN REKOMENDASI Kesmpulan}

Ikan endemik di Pulau Sumatera memiliki jumlah jenis yang sangat tinggi (66 jenis) tersebar di berbagai pulau dan perairan, sebanyak 13 jenis (20\%) mulai terancam punah. Pengelolaan dan upaya pelestarian terhadap ikan endemik masih sangat minim sekali sehingga keberadaannya di alam sering terabaikan. Untuk menjaga kelestarian sumberdaya ikan tersebut di Pulau Sumatera diperlukan pengelolaan secara insitu dan ex-situ. Pengelolaan secara in-situ diantaranya a) suaka perikanan, b) rehabilitasi lingkungan dan modifikasi habitat, c) pengendalian ikan introduksi, d) menyusun regulasi penangkapan ikan sedangkan ex-situ yaitu melalui domestikasi.

\section{Rekomendasi}

Untuk menjaga kelestarian ikan-ikan endemik yang terancam punah perlu dilakukan beberapa upaya perlindungan melalui:

Bagi daerah yang memiliki ikan endemik terancam punah, pemerintah daerah perlu menyusunregulasi tentang perlindungan habitat ikan endemik dan upaya konservasi jenis ikan tersebut. Hal ini dimaksudkan agar pengelolaan sumberdaya ikan endemik memiliki aspek legalitas yang kuat sehingga kelestariannya dapat dijaga dengan baik. Untuk menunjang kegiatan domestikasi dan restocking, beberapa daerah yang memiliki ikan endemik terancam punah, seharusnya daerah tersebut perlu mengembangkan hatchery-hatchery yang juga membudidayakan ikan-ikan endemik terancam punah.

\section{PERSANTUNAN}

Tulisan ini merupakan bagian dari penelitian dengan Judul "Kebijakan Peningkatan Produksi dan Konservasi Sumberdaya Ikan di Perairan Umum Daratan Paparan Sunda" yang berasal dari DIPA
Pusat Penelitian Pengelolaan Perikanan dan Konservasi Sumberdaya lkan tahun 2013.

\section{DAFTAR PUSTAKA}

Barus, T. A., Wahyuningsih, H., Ginting, E. M \& Simanjuntak, C.P.H. (2014). Ecobiological Review of Neolissochilus Sumatranus (Ikan Batak) (Weber and de Beaufort, 1916) In Asahan River, North Sumatera. Proceeding: The First International Seminar on Trends in Science and Science Education, p. 39-45.

Conservation Breeding Specialist Group. (2003). Conservation Assesment and Management Plan for Sumatran Threatened Species. Final Report. IUCN, SCC, Conservation Breeding Specialist Apple Valley, MN, USA. 117 p.

Direktorat Kawasan Konservasi Jenis Ikan. (2015). Pedoman Umum Restoking Jenis Ikan Terancam Punah. Direktorat Kawasan Konservasi Jenis Ikan, 67 hal.

Engelman, R., Pauly, D., Zeller, D., Prinn, R.G., Pinnegar, Z.K., \& Polunin, N.V.C. (2008). Introduction: Climate, people, ûsheries and aquatic ecosystems, (p.1-15) in N.V.C. Polunin (ed.) Aquatic Ecosystems: Trends and Global Prospects. Cambridge University Press, New York.

Groombridge, B. (1992). Global Biodiversity: Status of the Earth's Living Resources. A Report compiled by WCMC in collaboration with The Natural History Museum, London, IUCN, UNEP, WWF, and WRI. ChaPman \& Hall, London.

Hui, T.H. (1999). Rasbora vulcanus, a new species of cyprinid fish from central Sumatra.J. South Asian Nat. Hist, 4(2), 111-116.

http://fishbase.org (2015). Diunduh tanggal 10 Maret 2015.

IUCN (2001). The 2000 IUCN Red List of Threatened Species. http: //www' redlist. org/info sources qualitv.html, 5 I 8101.

Jenkins, A., Kullander, F.F. \& Tan, H.H. (2009).Osteochilus serokan. The IUCN Red List of Threatened Species 2009: e.T169509A6640239. http://dx.doi.org/10.2305/IUCN.UK.20092.RLTS.T169509A6640239.en 
Kartamihardja, E. S., Hedianto, D. A., \& Umar, C. (2015). Strategi Pemulihan Sumber Daya Ikan Bilih (Mystacoleucus padangensis) Dan Pengendalian Ikan Kaca (Parambassis siamensis) Di Danau Toba, Sumatera Utara, J. Kebijak. Perik.Ind. 7(2), 63-69.

Kottelat, M., Britz, R., Hui, T. H., \& Witte, K. E. (2006). Paedocypris, a new genus of Southeast Asian cyprinid fish with a remarkable sexual dimorphism, comprises the world's smallest vertebrate. Proceeding Biology Science, 273 (1589), 895-899.

Kottelat, M., Whitten, J.A., Wirjoamodjo, S., \& Kartikasari, A. N. (1996). Fishes of West Indonesia and Sulawesi. Periplus Edition Limited. Jakarta.

Kottelat, M., \& Whitten, T. (1996). Freshwater Biodiversity in Asia, with Special Reference to Fish. World Bank Technical Paper No. 343 break. $87 \mathrm{p}$.

Kottelat, M., Whiten, A.J., Kartikasari, S.N., \& Wirjoatmodjo, S. (1993). Freshwater Fishes of Western Indonesia and Sulawesi. Periplus Editions (HK) Ltd. In Collaboration with the Envinmental Management Development in Indonesia (EMDI) Project Minstry of State for Population and Environment, Republic of Indonesia. $291 \mathrm{p}$.

Kottelat, M. (1991). Notes on the taxonomy of some Sundaic and Indochinese species of Rasbora, with description of four new species (Pisces: Cyprinidae). Ichthyol. Explor. Freshwat, 2(2), 177191.

Kutarga, Z. W., Nasution, Z., Tarigan, R., \& Sirojuzilam. (2008). Kajian penataan ruang kawasan Danau laut Tawar dalam rangka pengembangan wilayah Kabupaten Aceh Tengah. Wahana Hijau, Jurnal Perencanaan dan Pengembangan Wilayah, 3(3), 106-115.

Lumbantobing, D. (2014). Four new species of Rasbora of the Sumatrana group (Teleostei: Cyprinidae) from northern Sumatra, Indonesia. Zootaxa, 3764 (1), 001-025.

McNeely, J.A., Miller, K.R., Reid, W.V., Mittermeier, R.A., \& Werner, T.B. (1990). Conserving the llorld's Biolo gical Diversity. IUCN, WRI, C.I., WWF-US, the World Bank. Gland, Switzerland, and Washington, D.C.

Muchlisin, Z.A., Thomy, Z., Fadli, N., Sarong, M.A., \& Siti-Azizah, M.N. (2013). DNA Barcoding of
Freshwater Fishes from Lake Laut Tawar, Aceh Province, Indonesia. Acta Ichthyologica et Piscatoria, 43(1), 21-29.

Moyle, P.B., \& Leidy, R.A. (1992). Loss of Biodiversity in Aquatic Ecosystem: Evidence from fish faunas. In Fledler. P. L and S. K. Jains (eds). Conservation Biology: The Theory and Practice of Nature Conservation, Preservation and management. Chapman and Hall, New York.

Nasution, S. H. (2015). Permasalahan dan Peluang Perbaikan Sistem Pengelolaan dan Konservasi Danau Laut Tawar. IPB Press.

Nur, B. (2011). Studi Domestikasi Dan Pemijahan Ikan Pelangi Kurumoi (Melanotaenia parva) Sebagai Tahap Awal Upaya Konservasi Ex-Situ. Prosiding Forum Nasional Pemacuan Sumber Daya IkanllI, KSI 22(1-9).

Prianto, E., Sulaiman, P. S., Puspasari, R., \& Zulfia, N. (2014). Ikan Merah, Spesies Baru Kandiat Ikan Hias. TROBOSAqua Edisi 24 Tahun II. Hal 26-27.

Prianto, E., Kartamihardja, E. S., Umar, C., Puspasari, R., Oktaviani, D., Sulaeman, P. S., Kasim, K., Zulfia, N., Rachmawati, P., Fahmi, Z., \& Budi, E.K. (2013). Kebijakan Peningkatan Produksi Dan Konservasi Sumberdaya Ikan Di Perairan Umum Daratan Paparan Sunda. Laporan Teknis. Pusat Penelitian Pengelolaan Perikanan dan Konservasi Sumberdaya lkan. 109 hal.

Prianto, E., \& Husnah. (2009). Penambangan Timah Inkonvensional: Dampaknya Terhadap Kerusakan Biodiversitas Perairan Umum di Pulau Bangka. Prosiding Forum Perairan Umum Indonesia VI. Balai Riset Perikanan Perairan Umum. Hal 271278.

Pusat Penelitian Pengelolaan Perikanan Dan Konservasi Sumberdaya lkan. (2013). Pengelolaan Sumber Daya Ikan Bilih Berbasis Ko-Manajemen Di Danau Toba Provinsi Sumatera Utara. Petunjuk Teknis. 49 hal.

Suwelo, I. S. (2005).Spesies Ikan Langka Dan Terancam Punah Perlu Dilindungi Undang-Undang. Jurnal IImu-ilmu Perairan dan Perikanan Indonesia, 12 (2), 153-160.

Utomo, A.D., Kaban, S., \& Hartoto, D.I. (2008). Correlation of water level fluctuation to physicochemical features of Lubuk Lampam floodplain.fisheries ecology and management of 
Lubuk Lampam floodplain Musi River, South Sumatera. Research Institute for Inland Waters Fisheries. p. 8-15.

Wargasasmita, S. (2002). Ikan Air Tawar Endemik Sumatra yang Terancam Punah (The freshwater fishses of endemic of Sumatra that threatened species). Jurnal Ikhtiologi Indonesia, 2(2): 41-49.

Wibowo, A., Ahnelt, A., \& Kartamihardja, E. S. (2016). Pectenocypris nigra, a new danionine species
(Teleostei: Cyprinidae: Danioninae) from Sumatra (Indonesia). Acta Biologica Turcica, 29(4), 137-142.

Yulfiperius. (2006). Domestikasi dan Pengembangbiakan Dalam Upaya Pelestarian lkan Lalawak (Barbode sp). Sekolah Pasca Sarjana Institut Pertanian Bogor. Disertasi. 157 hal.

Zakaria-Ismail, M. (1994). Zoogeography and biodiversity of the freshwater fishes of Southeast Asia. Hydrobiologia, 285: 41 -48. 


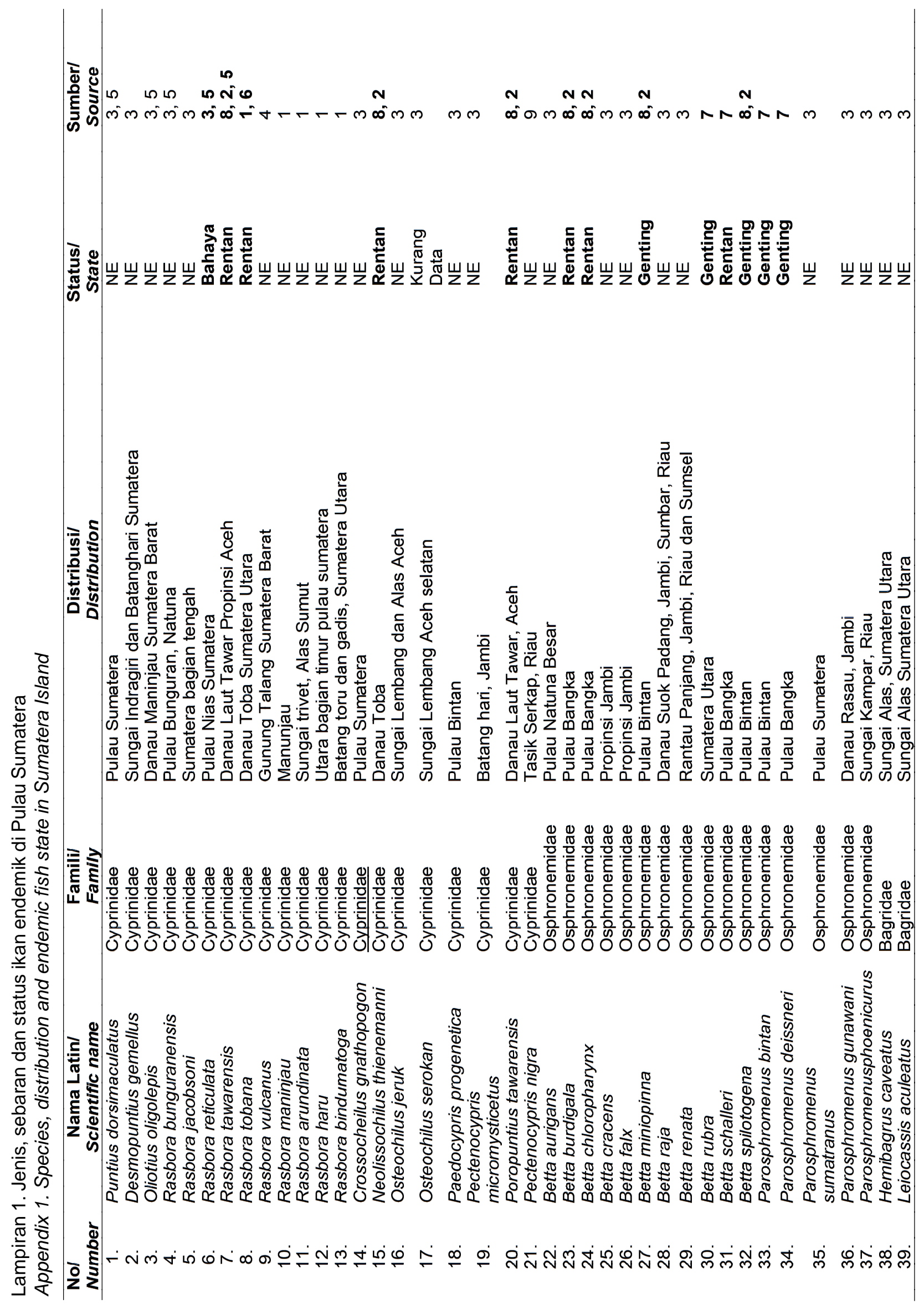


Ln

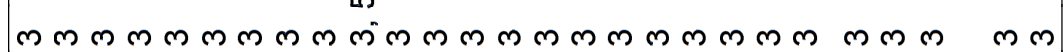
щ

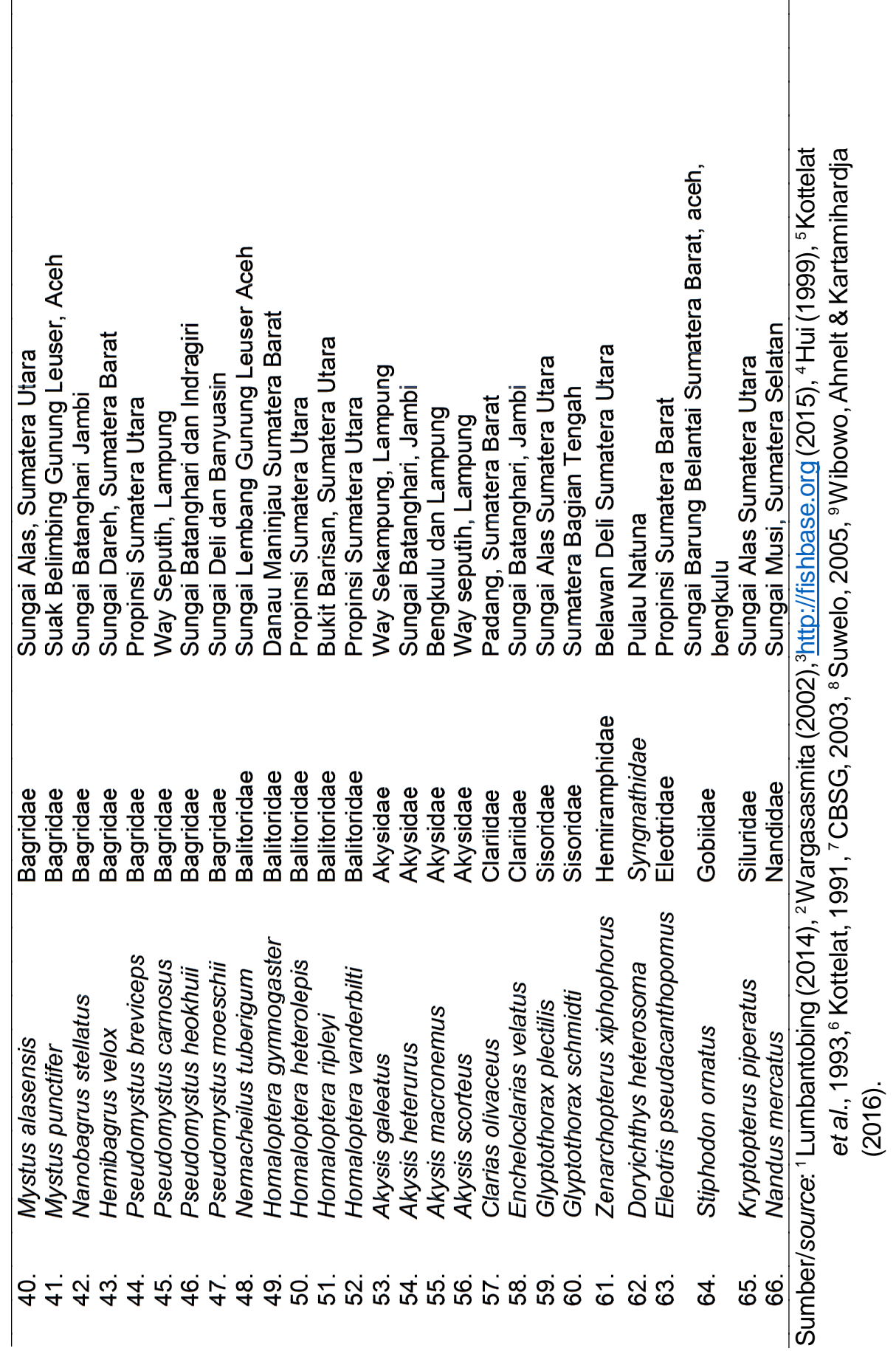

